\title{
Initial treatment of purulent meningitis in infants 1 to 3 months of age
}

\author{
JAMES E. KOVACS, D.O. \\ Kingston, Pennsylvania \\ MICHAEL E. RYAN, D.O. \\ Danville, Pennsylvania
}

The choice of antibiotic in the treatment of purulent meningitis in infants is based on the child's age and, until bacterial cultures of cerebrospinal fluid can be obtained, on the probable causative organism. A retrospective review of 16 infants between 4 weeks and 14 weeks of age over a 21-year period revealed that Hemophilus influenzae type b was the most commonly isolated bacterial agent; Streptococcus pneumoniae, Neisseria meningitis, and group B streptococcus were lessfrequent causes of meningitides in this age group. To combat purulent meningitis in infants between 1 and 2 months of age, ampicillin plus cefotaxime can be recommended as antibiotic therapy for full-term infants who have no neonatal complications or history of previous infection. After 2 months of age, ampicillin plus chloramphenicol are the antibiotics of choice.

The early antibiotic treatment for purulent meningitis, until bacterial growth from cerebrospinal fluid can be confirmed, is based on the patient's age and the probable organism causing the disease. In infants younger than 1 month old, gram-negative coliforms, group B streptococci, and Listeria monocytogenes are the most frequent causes of purulent meningitis. Parenteral ampicillin sodium plus an aminoglycoside can be recommended for this neonatal group. ${ }^{1,2}$ The best initial antibiotic treatment of purulent meningitis for patients between 1 and 3 months of age, however, is more complex, partly because of differences of opinion regarding the causative organisms in this age group and partly because of lack of differentiation in some studies among this age group, neonates, and older infants.

Proper age-dependent antibiotic therapy is critical to reducing the high morbidity and mortality in this age group. This paper reviews the relative incidence of causative organisms of purulent meningitis in infants between 4 and 14 weeks of age. It also considers the empiric antibiotic therapy for this age group.

\section{Causative organisms \\ Retrospective study}

We reviewed the medical records of patients discharged from Geisinger Medical Center in Danville, Pennsylvania, between 1963 and 1983 after having been treated for purulent meningitis; only patients who were between 4 and 14 weeks of age at the time of initial lumbar puncture were included in the study. Patients with positive bacterial growth from the cerebrospinal fluid (CSF) or with positive countercurrent immunoelectrophoresis for Hemophilus influenzae type b, Neisseria meningitidis group A or C, Streptococci pineumoniae, or group B streptococcus, or who had been pretreated with antibiotics and had cloudy or purulent CSF with a leukocyte count greater than $500 / \mathrm{cu}$. mm., protein level greater than $200 \mathrm{mg}$./dl., and glucose value less than $35 \mathrm{mg}$./dl. were included. Patients were excluded from the study if they had previously diagnosed sepsis or meningitis prior to 28 days of age, myelomeningocele, hydrocephalus within the first 28 days, or ventriculoperitoneal shunt, or if they had been of less than 37 weeks' gestation or had been small for gestational age.

Sixteen infants met the criteria for inclusion in the study (Table 1 ). The causative organism was 


\begin{tabular}{|c|c|c|c|c|c|c|}
\hline \multirow[b]{2}{*}{ Organism } & \multirow[b]{2}{*}{ Age in days } & \multicolumn{5}{|c|}{ Cerebrospinal Fluid } \\
\hline & & Leukocytes & $\begin{array}{c}\text { Percent } \\
\begin{array}{c}\text { polymorphonuclear } \\
\text { leukocytes }\end{array}\end{array}$ & $\begin{array}{c}\text { Percent } \\
\text { lymphocytes }\end{array}$ & Protein & Glucose \\
\hline \multirow{9}{*}{ Haemophilus influenzae } & 35 & 180 & 65 & 35 & 47 & 2 \\
\hline & 39 & 5,850 & 91 & 9 & 55 & 6 \\
\hline & 45 & 16,000 & 92 & 8 & - & - \\
\hline & 48 & 8,700 & 98 & 2 & 222 & 0 \\
\hline & 72 & 3,040 & 89 & 11 & 418 & 0 \\
\hline & 76 & 531 & 70 & 30 & 2,500 & 37 \\
\hline & 82 & 11,860 & 100 & 0 & 510 & 44 \\
\hline & 85 & 5,400 & 96 & 4 & 177 & 10 \\
\hline & 97 & 11,500 & 93 & 7 & 132 & 15 \\
\hline \multicolumn{7}{|l|}{ Streptococcus } \\
\hline \multirow[t]{3}{*}{ pneumoniae } & 29 & 100 & 93 & 7 & 118 & 22 \\
\hline & 34 & 18,400 & 100 & 0 & 1,500 & 8 \\
\hline & 66 & 2,870 & 97 & 3 & 238 & 5 \\
\hline \multirow[t]{2}{*}{ Neisseria meningitidis } & 44 & 964 & 92 & 8 & 550 & 8 \\
\hline & 92 & 12,960 & 91 & 9 & - & 0 \\
\hline Group B streptococcus & 29 & 657 & 98 & 2 & 188 & 0 \\
\hline No growth & 54 & 1,700 & 62 & 38 & 214 & 23 \\
\hline
\end{tabular}

isolated from CSF in 15 (94 percent) of them. $H$. influenzae type $\mathrm{b}$, the most common pathogen, was isolated from 9 (56 percent) of the 16 patients. $S$. pneumoniae was only one-third as prevalent, being found in 3 (19 percent of the infants.) $N$. meningitidis was present in the CSF of 2 patients (13 percent), and group B streptococcus was found in 1 infant ( 6 percent). No gram-negative coliforms were isolated from CSF.

Of the 16 patients in the study, 7 were between 1 and 2 months old. $H$. influenzae type $\mathrm{b}$ was the causative organism in 4 of the 7 , (57 percent). A $\beta$ lactamase-producing strain was isolated in the youngest patient, who was 35 days of age.

\section{Review of the literature}

In the 1- to 2-month age group, Friedman and Fleisher ${ }^{3}$ reported that in 5 of 7 cases ( 71 percent), the offending organism was $H$. influenzae, with the remaining 2 cases due to group B streptococci. Enzenauer and $\mathrm{Bass}^{4}$ found that meningitis was caused by $H$. influenzae in 7 of 16 infants (44 percent), by group B streptococci in 5 (31 percent), and by $S$. pneumoniae in 3 (19 percent). Baumgartner and coworkers ${ }^{5}$ found these organisms to occur with equal frequency $(n=2)$ in infants 4 and 5 weeks old who had bacterial meningitis. However, Nelson ${ }^{6}$ showed group B streptococcus as the prevailing organism in infants from 1 to 2 months old, with $H$. influenzae a poor second. In infants from 2 to 3 months old, the reverse was true. Pneumococci were the third ranking cause in both age groups. Most authors noted that group B streptococcus was not a usual cause of meningitis after 3 months of age. ${ }^{6}$

In 3 reported cases of Escherichia coli meningitis in infants older than 1 month of age reviewed by Enzenauer and Bass, ${ }^{4}$ each patient had had a low birth weight and a neonatal course complicated by infection. Baumgartner and associates, ${ }^{5}$ however, found this organism in 3 of 9 cases in the 1- to 2 month- old infants. Nelson ${ }^{6}$ found $E$. coli in about 8 percent of 64 cases in this age group.

\section{Choice of antibiotic therapy and discussion}

A physician's selection of antibiotic has become more difficult as the incidence of $\beta$-lactamase-producing strains of $H$. influenzae type $\mathrm{b}$ increases nationwide. Prior to 1974, all strains of $H$. influenzae that caused meningitis were assumed to be uniformly sensitive to ampicillin, but an average of 25 percent of $H$. influenzae type b strains in the United States are now resistant to that drug. ${ }^{2}$ Resistance of some strains of the organism to both ampicillin and chloramphenicol has been reported rarely in Asia, Europe, and the U.S., but the incidence in Spain, at least, appears to be increasing. ${ }^{6,7}$ Some $E$. coli strains are also resistant to ampicillin. ${ }^{5}$ In addition, an increasing number of $S$. pneumoniae isolates are resistant to the penicillin. ${ }^{1,6}$

There has been some speculation about the use of ampicillin and choramphenicol for group B streptococci following a study of their in vitro antagonism. ${ }^{8}$ In addition, the unpredictable metabolism of chloramphenicol in this age group requires serum concentrations measured and dosage adjustments accordingly. Cefotaxime apparently does not inhibit early bactericidal activity by ampicillin against group B streptococci. ${ }^{8}$ Although cefotaxime is ineffective against $S$. pneumoniae and group B streptococci that cause meningitis, ${ }^{9}$ ampicillin re- 
sistance is still rare in these organisms. Empiric antibiotic therapy must provide coverage against these organisms as well as against $H$. influenzae type b. Because $E$. coli and other members of Enterobacteriaceae are uncommon causes of purulent meningitis in noncompromised infants older than 1 month old, gentamicin usually is not indicated beyond this age.

The use of aminoglycosides may be appropriate for premature, small for gestational age, immunodeficient, neurologically anomalous, or previously infected infants older than 1 month, but the microbiologic spectrum of meningitis in noncompromised infants 1 to 2 months of age would seem to be covered well by ampicillin and cefotaxime. Beyond 3 months of age, group B streptococcus is an uncommon pathogen for purulent meningitis, so ampicillin and chloramphenicol can be recommended.

1. Congeni, B.L.: The treatment of bacterial meningitis. Pediatr Ann 15:456-7, 460 Jun 86

2. Krugman, S., et al.: Infectious diseases of children. Ed. 8. St. Louis, C.V. Mosby Co., 1987
3. Friedman, A., and Fleisher, G.: Meningitis. Update of recommendations for the neonate. Clin Pediatr 19:395-7, Jun 80

4. Enzenauer, R.W., and Bass, J.W.: Initial antibiotic treatment of purulent meningitis in infants 1 to 2 months of age. Am J Dis Child 137:1055-6, Nov 83

5. Baumgartner, E.T., Augustine, R.A., and Steele, R.W.: Bacterial meningitis in older neonates. Am J Dis Child 137:1052-4, Nov 83

6. Nelson, J.D.: Emerging role of cephalosporins in bacterial meningitis. Am J Med 79(Suppl. 2A):47-51, 9 Aug 85

7. Campos, J., et al.: Multiply resistant Haemophilus influenzae type b causing meningitis. Comparative clinical and laboratory study. J Pediatr 108:897-902, 1986

8. Weeks, J.L., Mason, E.O., Jr., and Baker, C.J.: Antagonism of ampicillin and chloramphenicol for meningeal isolates of group B streptococci. Antimicrob Agents Chemother 20:281-5, Sep 81

9. McCracken, G.H., Jr., Nelson, J.D., and Grimm, L.: Pharmacokinetics and bacteriological efficacy of cefoperazone, ceftriaxone, and moxalactam in experimental Streptococcus pneumoniae and Haemophilus influenzae meningitis. Antimicrob Agents Chemother 21:262-7, Feb 82

Dr. Kovacs is a family practice resident at Wyoming Valley Family Practice Hospital, Kingston, Pennsylvania. At the time this paper was written, he was a student at the University of Health Sciences, College of Osteopathic Medicine, Kansas City, Missouri. Dr. Ryan is director, pediatric subspecialties/pediatric infectious diseases, Geisinger Medical Center, Danville, Pennsylvania.

Dr. Ryan, Geisinger Medical Center, Danville, Pennsylvania 17822 . 


\section{non-insulin-dependent}

\section{Diabetes and fasting glucose}

Fasting hyperglycemia is largely due to hepatic overproduction of glucose. MicronaSE has been shown to decrease elevated basal rates of hepatic glucose production, and this may account for its ability to reduce fasting hyperglycemia. MICRONASE improves 24-hour control of both postprandial and fasting blood glucose levels. MICRONASE usually provides 24-hour control of blood glucose levels with a once-a-day dosage.

All sulfonylureas, including MiCRONASE, can cause severe hypoglycemia. Proper patient selection, dosage, and instructions are important.

No other oral antidiabetic agent fits the realities of life better than

Micronase

Tablets (glyburide)

Usual starting dosage $-2.5 \mathrm{mg}$ to $5 \mathrm{mg}$ once a day

When diet alone fails...MICRONASE

Please see adjacent page for brief summary of prescribing information. 

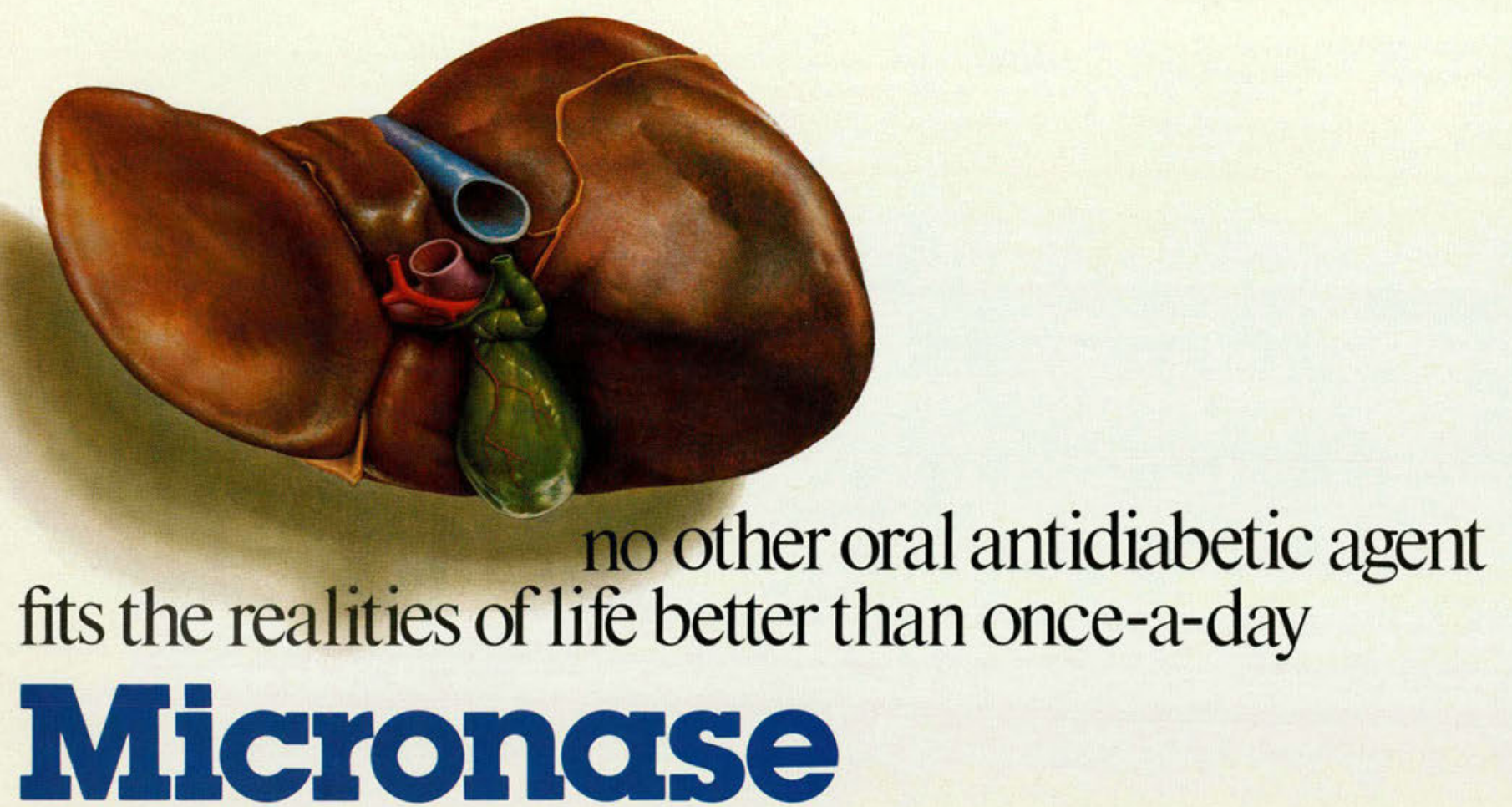

Some patients, particularly those receiving more than $10 \mathrm{mg}$ daily, may have a more satisfactory response with twice-a-day dosage.

\section{Micronase Tablets (glyburide)}

CONTRAINDICATIONS: MICRONASE Tablets are contraindicated in patients with: 1. Known hypersensitivity or allergy to the drug. 2. Diabetic ketoacidosis, with or without coma. This condition should be treated with insulin. 3. Type I diabetes mellitus, as sole therapy.

SPECIAL WARNING ON INCREASED RISK OF CARDIOVASCULAR MORTALITY: The administration of oral hypoglycemic drugs has been reported to be associated with increased cardiovascular mortality as compared to treatment with diet alone or diet plus insulin. This warning is based on the study conducted by the University Group Diabetes Program (UGDP), a long-term prospective clinical trial designed to evaluate the effectiveness of glucose-lowering drugs in preventing or delaying vascular complications in patients with noninsulin-dependent diabetes. The study involved 823 patients who were randomly assigned to one with noninsulin-dependent diabetes. The study involved 823 pa:
of four treatment groups (Diabetes, 19 (Suppl 2: $747-830,1970$ ).

UGDP reported that patients treated for 5 to 8 years with diet plus a fixed dose of tolbutamide (1.5 grams per day) had a rate of cardiovascular mortality approximately $2 \frac{1}{2}$ times that of patients treated with diet alone. A significant increase in total mortality was not observed, but the use of tolbutamide was discontinued based on the increase in cardiovascular mortality, thus limiting the opportunity for the study to show an increase in overall mortality. Despite controversy regarding the interpretation of these results the findings of the UGDP study provide an adequate basis for this warning. The patient should be informed of the potential risks and advantages of MICRONASE and of alternative modes of therapy.

Although only one drug in the sultonylurea class (tolbutamide) was included in this study, it is prudent from a satety standpoint to consider that this warning may apply to other oral hypoglycemic drugs in this class. in view of their close similarities in mode of action and chemical structure.

PRECAUTIONS: General-Hypoglycemia: All sultonylureas are capable of producing severe hypoglycemia Proper patient selection and dosage and instructions are important to avoid hypoglycemic episodes. Renal or hepatic insufficiency may increase the risk of serious hypoglycemic reactions. Elderly. debilitated or malnourished patients, and those with adrenal or pituitary insufficiency, are particularly susceptible to the hypoglycemic action of glucose-lowering drugs. Hypoglycemia may be difficult to recognize in the elderly and in people who are taking beta-adrenergic blocking drugs. Hypoglycemia is more likely to occur when caloric intake is deficient, after severe or prolonged exercise, when alcohol is ingested, or when more than one glucose lowering drug is used. Loss of Control of Blood Glucose. In diabetic patients exposed to stress such as fever, trauma, infection or surgery. a loss of control may ocçur. It may then be necessary to discontinue MICRONASE and administer insulin. Adequate adjustment of dose and adherence to diet should be assessed before classifying a patient as a secondary failure. Information for Patients. Patients should be informed of the potential risks and advantages of MICRONASE and of alternative modes of therapy. They also should be informed about the importance of adherence to dietary instructions, of a regular exercise program, and of regular testing of urine and/or blood glucose. The risks of hypoglycemia, its symptoms and treatment and conditions that predispose to its development should be explained to patients and responsible family members. Primary and secondary failure should also be explained. Laboratory Tests: Response to MICRONASE Tablets should be monitored by frequent urine glucose tests and periodic blood glucose tests. Measurement of glycosylated hemoglobin levels may be helptul in some patients. Drug interactions: The

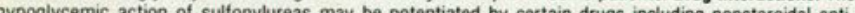
nflammatory agents ar inflammatory agets al col, probenecid, coumarins, monoamine oxidase inhibitors, and beta adrenergic blocking agents. Certain drugs tend to produce hyperglycemia and may lead to loss of control. These drugs include the thiazides and other diuretics, corticosteroids, phenothiazines, thyroid products, estrogens, oral contraceptives, phenytoin, nicotinic acid, sympathomimetics, calcium channel blocking drugs, and isoniazid. A potential interaction between oral miconazole and oral hypoglycemic agents leading to severe hypoglycemia has been reported. Carcinogenesis, Mutagenesis, and Impairment of Fertility: Studies in rats at doses up to $300 \mathrm{mg} / \mathrm{kg} /$ day for 18 months showed no carcinogenic effects. Glyburide is nonmutagenic when studied in the Salmonells microsome test (Ames test) and in the DNA damage/alkaline elution assay. Pregnancy: Teratogenic Effects. Pregnancy Category B. Reproduction studies in rats and rabbits have revealed no evidence of impaired fertility or harm to the fetus due to glyburide. There are no adequate and well controlled studies in pregnan women. This drug should be used during pregnancy only if clearly needed. Insulin should be used during pregnancy to maintain blood glucose as close to normal as possible. Nonteratogenic Effects: Prolonged severe hypoglycemia ( 4 to 10 days) has been reported in neonates born to mothers who were receiving a sulfonylurea drug at the time of delivery. MICRONASE should be discontinued at least two weeks before the expected delivery date. Nursing Mothers: Some sulfonylurea drugs are known to be excreted in human milk. Insulin therapy should be considered. Pediatric Use: Safety and effectiveness in children have not been established.

ADVERSE REACTIONS: Hypoglycemia: See Precautions and Overdosage sections. Gastrointestinal Reactions: Cholestatic jaundice may OCCur rarely. MICRONASE Tablets should be discontinued if this occurs Gastrointestinal disturbances reactions, having occurred in $1.8 \%$ of treated patients during clinical trials. They tend to be dose-related and reactions, having occurred in $1.8 \%$ of treated patients during clinical trials. They tend to be dose-related and
may disappear when dosage is reduced. Liver function abnormalities, including isolated transaminase elevations, have been reported. Dermatologic Reactions: Allergic skin reactions, e.g. pruritus, erythema urticaria, and morbilifiform or maculopapular eruptions, occurred in $1.5 \%$ of treated patients during clinica trials. These may be transient and may disappear despite continued use of MICRONASE; if skin reactions persist, the drug should be discontinued. Porphyria cutanea tarda and photosensitivity reactions have been

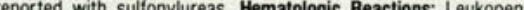
peported wit sulonye ther (1) Metabolic Reactions: Hepatic porphyria and disulfiram-like reactions have been reported with sulfonylureas; however hepatic porphyria has not been reported with MICRONASE and disulfiram-like reactions have been reported very rarely. Cases of hyponatremia have been reported with glyburide and all other sulfonylureas, most often in patients who are on other medications or have medical conditions known to cause hyponatremia or increase release of antidiuretic hormone. (SIADH) secretion has been reported with certain other sulfonylureas, and it has been suggested that these sulfonylureas may augment the peripheral (antidiuretic) action of $\mathrm{ADH}$ and lor increase release of $\mathrm{ADH}$

OVERDOSAGE: Overdosage of sulfonylureas, including MICRONASE Tablets, can produce hypoglycemia. If hypoglycemic coma is diagnosed or suspected, the patient should be given a rapid intravenous injection of concentrated $(50 \%$ ) glucose solution. This should be followed by a continuous infusion of a more dilute (10\%) glucose solution at a rate which will maintain the blood glucose at a level above $100 \mathrm{mg} / \mathrm{dL}$. Patients should be closely monitored for a minimum of 24 to 48 hours, since hypoglycemia may recur after apparent clinical recovery.

Caution Federal law prohibits dispensing without prescription. Store at controlled room temperature $15^{\circ}-30^{\circ} \mathrm{C}\left(59^{\circ}-86^{\circ} \mathrm{F}\right.$. Dispensed in well closed containers with safety closures. Keep container tightly closed. For additional product information see your Upjohn representative.

\section{Upjohn}

THE UPJOHN COMPANY, Kalamazoo, MI 49001, USA 


\section{New Products}

continued from page 530/34

contact Welch Allyn, Inc., Medical Division, 4341 State Street Road, P.O. Box 220, Skaneateles Falls, New York 13153-0220 315) 685-8351.

\section{Skin surface thermometer}

This liquid crystal thermometer adheres to any area of the body for constant monitoring of skin surface temperature. DermaTemp Skin Surface Monitor takes only 15 seconds to show the initial reading and continues to measure temperature as long as the strip is in place. It enables the comparison of local blood flow differences for use in evaluation of circulation in a burn area, detection of potential circulatory disorder or problems with inflammation after a sports injury, determination of patency of femoral bypass grafts in vascular surgery, and early detection of bed sores. For more information on the DermaTemp Skin Surface Monitor, contact American Thermometer Company, 125 Bacon Street, Dayton, Ohio 45402 (513) 228-2817.

\section{Disposable biologic test pack}

A pre-assembled, disposable biologic challenge pack for testing either steam or ethylene oxide sterilizers is now available. Proof Dual-Pack is is ready to use, eliminates the inconsistencies which can be associated with the assembly of conventional packs, and can be used to test either steam or gas cycles. Included in the pack is a Proof Plus ${ }^{\circledast}$ self-contained biologic indicator, which features a large, clear vial, vivid color change, a builtin chemical indicator, and fast readout of results. For further information on Proof Dual-Pack ${ }^{(i)}$, contact AMSCO/Medical Products Division, 2820 West 23rd Street, Erie, Pennsylvania 16514 (800) 458-0506, or in Pennsylvania (800) 352-0097.

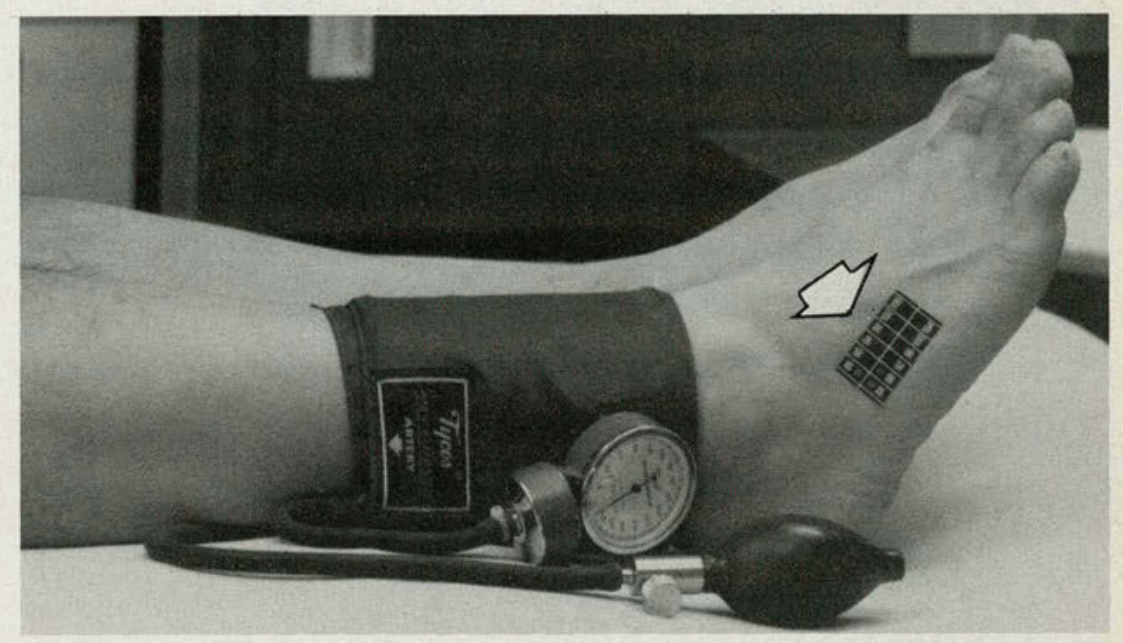

\title{
American Osteopathic Association Bureau of Research
}

\section{Request for proposals}

The Bureau of Research invites applications for funds to support research that has demonstrable relevance to osteopathic theory and practice. It is the applicant's responsibility to demonstrate that relevance.
Proposals for the grant cycle must be submitted to the address below by midnight, December 1, 1987. Application guidelines and forms are in the 1987 edition of the Osteopathic Research Handbook which is available from the:

\author{
Division of Research \\ Department of Education \\ American Osteopathic Association \\ 142 East Ontario \\ Chicago, IL 60611-2864
}

312-280-5864

or

800-621-1773 


\section{A defense against cancer can be cooked up in your kitchen.}

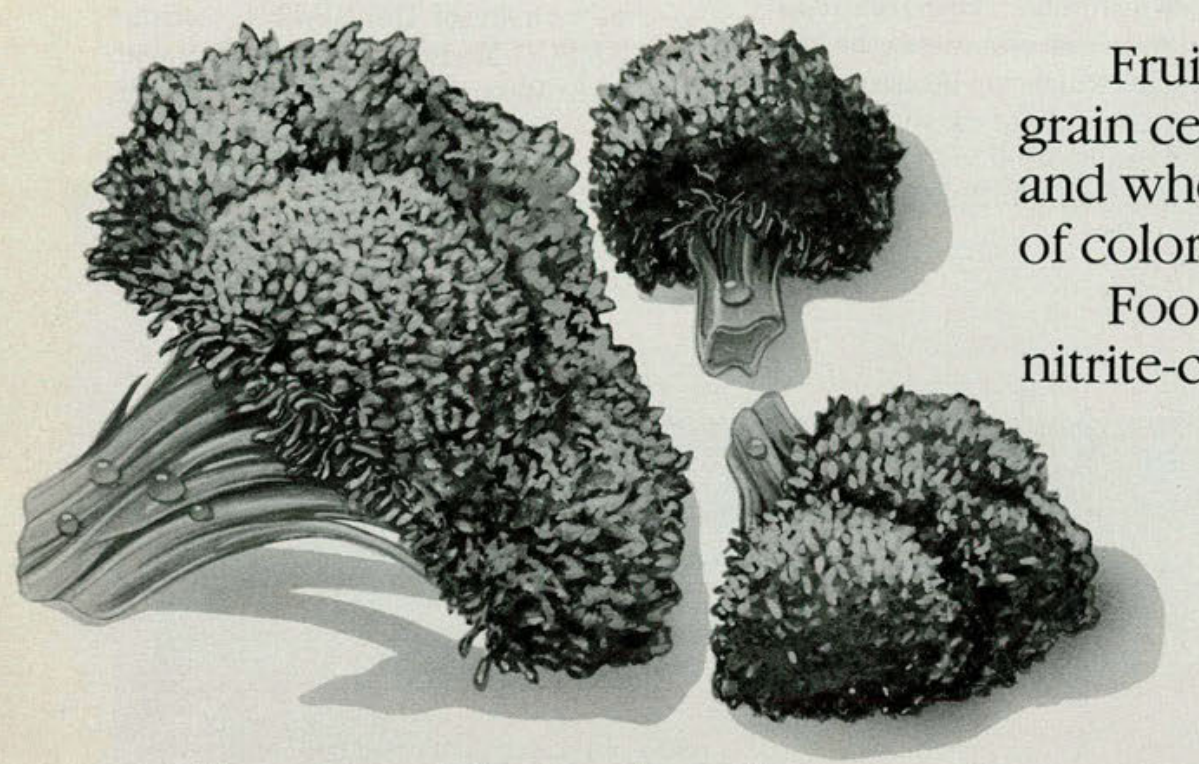

Fruits, vegetables, and whole-

There is evidence that diet and cancer are related. Some foods may promote cancer, while others may protect you from it.

Foods related to lowering the risk of cancer of the larynx and esophagus all have high amounts of carotene, a form of Vitamin A which is in cantaloupes, peaches, broccoli, spinach, all dark green leafy vegetables, sweet potatoes, carrots, pumpkin, winter squash and tomatoes, citrus fruits and brussels sprouts.

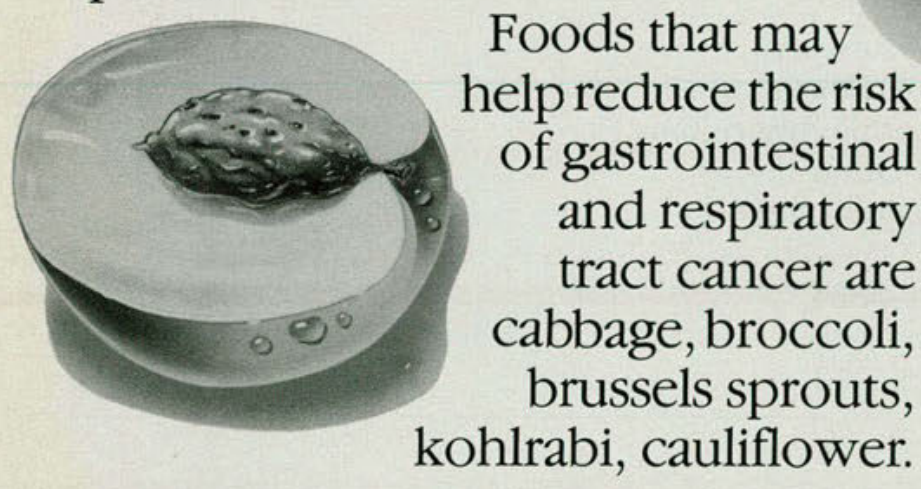

fish and

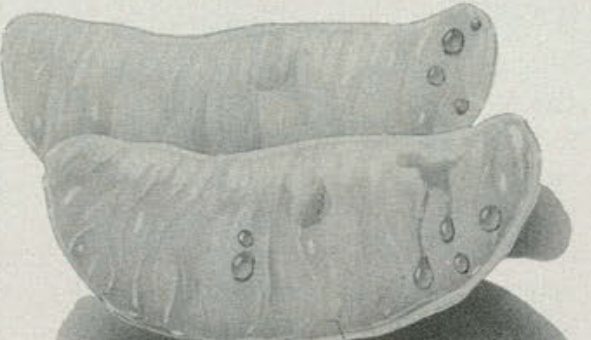

types of sausages smoked by traditional methods should be

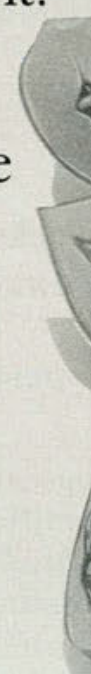
eaten in moderation.

Be moderate in consumption of alcohol also.
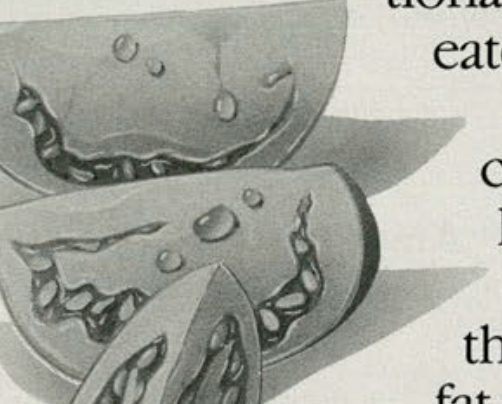
fat and don't be fat.

Weight reduction may lower cancer risk. Our 12- year study of nearly a million Americans uncovered high cancer risks particularly among people $40 \%$ or more overweight.

Now, more than ever, we know you can cook up your own defense against cancer. So eat healthy and be healthy.

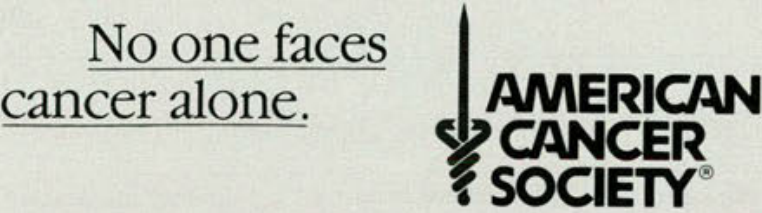




\section{Medi-notes}

continued from page $\mathbf{5 4 0 / 6 2}$

creased muscle strength and possibly even demineralization of bone.

Like anything else, rest can be abused.

Less rest for low back pain. Emerg Med 19:72-3, 30 Mar 87

\section{Strategy for managing chronic pelvic pain}

Chronic pelvic pain often fails to respond to traditional medical or surgical treatment. The pain management center approach, which has been used successfully to relieve cancer pain and headache, can be adapted to the treatment of chronic pelvic pain.

First, a complete history taking and thorough physical examination should be performed. Psychologic factors should be addressed. Laparotomy usually is necessary for diagnosis.

An interdisciplinary approach is used in management. Modalities include physical therapy, biofeedback, exercise, psychologic therapy, acupuncture, or relaxation training. The patient takes an active role in pain management. A pilot study of one pain management center showed that at the end of the 6-week program described, pain usually was reduced substantially. The patients learned to function at a normal physical and psychosocial level.

Rapkin, A.J., and Kames, L.D.: The pain management approach to chronic pelvic pain. $J$ Reprod Med 32:323-7, May 87

\section{Pressure ulcers}

Pressure ulcers have been noted by physicians since antiquity; they were, in fact, treated by Hippocrates. Despite all our modern advances, a recent study at Johns Hopkins Hospital revealed a 4.7 percent prevalence of pressure ulcers among hospitalized patients.
Admittedly, these ulcers remain difficult and frustrating to treat. There appears to be no consensus on the best therapeutic method. In general, the best treatment is prevention. The pressure sores occur when prolonged compression or shear is applied to the skin of predisposed patients. Prevention requires identification of patients at risk in institutions, through surveillance and nursing care. The article provides an assessment scale for identifying such patients. Once pressure ulcers occur, treatment decisions are based on the depth of the ulceration. Management consists of removal of pressure, debridement of the wound, and reduction of wound bacteria counts. The efficacy of topical agents and expensive bed support systems remains to be determined.

Xakellis, G.C., Jr., and Garzone, P.: Pressure ulcers. Am Fam Physician 35:159-64, Apr 87

\section{Diagnosis and treatment of acute knee injuries}

The authors correctly point out that in the first minute after an athlete sustains an injury, valuable information can be gained that is hard to obtain later, when increased swelling, muscle spasms, and pain are present. The immediate examination should focus on stability, neurologic function, vascular status, false motion, or gross deformities. Inability to extend the knee fully immediately after injury may indicate a displaced meniscal tear. One should not attempt to unlock a locked knee while the player is still on the field. A simple but thorough ligament examination can be made quickly with the use of the Lachman test, posterior drawer test at 90 degrees of flexion, and varus and valgus stress tests.

Immediate treatment in the locker room should consist of compression, elevation, and the application of ice. The pressure of any sign or symptom referable to neurovascular injury necessitates immediate referral to an orthopedic surgeon. The article presents a comprehensive overview of both the examination and treatment of this common form of athletic injury.

Bassett, F.H., III., Nygaard, A.L., and Zarins, B.: Optimal care for acute knee injuries. Patient Care 22:32-49, 26 Feb 87

\section{Anticholinergic drugs in the elderly}

Impairment of ability to learn new material is a feature of anticholinergic drugs, even at routine clinical doses. In a double-blind crossover trial, elderly normal subjects complained of and demonstrated more impairment of memory while they were taking trihexyphenidyl than they did when receiving amantadine. The deficits in memory function were consistent with those associated with anticholinergic drugs in other reported studies.

From these results it would appear that anticholinergic drugs should be avoided whenever possible in the elderly, especially if dementia is present.

McEvoy, J.P., et al.: Effects of amantadine and trihexyphenidyl on memory in elderly norma volunteers. Am J Psychiatr 144:573-7, May 87

\section{Laboratory differentiation among anemias}

A mild anemia is usually asymptomatic, so a laboratory report may be the first indication of its existence. When anemia is thought to be present but the history and physical examination fail to show the cause, systematic use of laboratory tests can determine the type of anemia present. An approach that helps to differentiate among anemias is de- 
scribed. The mean corpuscular volume (MCV) provides a valuable aid in identification of iron deficiency. When the MCV is low, determination of transferrin saturation and plasma ferritin help to distinguish the microcytic anemias. The reticulocyte index provides a guide to differentiation between hemolytic and hypoproliferative anemias and maturation abnormalities. If the MCV is elevated, the blood smear is helpful in separating macrocytes. A guide to iron therapy in iron-deficient states is provided.

English, E.C.: Anemia. J Fam Pract 24:521-7, 1987

\section{Moderate alcohol intake and risk of breast cancer}

In 1980 diet information that included use of beer, wine, and liquor was obtained by independently validated questionnaires from 89,538 United States women aged 34 to 59 years without a cancer history. Follow-up during the next 4 years revealed 601 cases of breast cancer among these women. The age-adjusted relative risk of breast cancer among the women who consumed 5 to $14 \mathrm{gm}$. of alcohol per day (about 3 to 9 drinks a week) was 1.3 (95 percent confidence limits, 1.1 and 1.7). The relative risk from consumption of $15 \mathrm{gm}$. alcohol or more daily was 1.6. The relationship was not altered materially by adjustment for various nutritional factors or known risk factors for breast cancer.

These findings are similar to those of most case-control studies. Viewed collectively, these data suggest that alcohol consumption may increase the risk of breast cancer.

Willett, W.C., et al.: Moderate alcohol consumption and the risk of breast cancer. N Engl J Med $316: 1174-80,7$ May 87

\section{More on the relationship of alcohol consumption and breast cancer}

This investigation studied the relationship between moderate alcohol consumption and breast cancer in the Epidemiologic Follow-up Study of the National Health and Nutrition Examination Survey, which was a cohort study based on a United States population sample. The analysis included 7,188 women aged 25 to 74 years examined 1971 through 1975. Median follow-up of 10 years showed 121 cases of breast cancer. Relative risks of breast cancer were estimated at 1.4 for the lowest level of consumption, 1.5 for moderate consumption, and 1.6 for the highest level, as compared to no drinking. Adjustment for various dietary factors or known risk factors did not materially affect these estimates.

Results of this study are consistent with those of two other cohort studies and several case-control studies. They suggest that an excess risk of breast cancer of about 50 to 100 percent is associated with moderate alcohol intake.

Schatzkin, A., et al.: Alcohol consumption and breast cancer in the Epidemiologic Follow-up Study of the First National Health and Nutrition Examination Survey. N Engl J Med 316:1169-73, 7 May 87 


\section{Coming in ...}

\section{THE DO}

Though death or illness is difficult on anyone, the death or debilitating illness of a physician creates a number of extenuating circumstances. The September issue of The $D O$ examines ways that physicians can lighten the burden on their families, patients, and themselves. Included in the issue is information on estate planning, physicians as patients, and closing a practice. Also in September is a commencement roundup of the osteopathic colleges.

\section{JAOA}

Mixed connective tissue disease: Report of a case with fatal outcome

Meperidine-induced hypereosinophilia: Report of a case

The Papanicolaou smear versus colposcopy for evaluation of the uterine cervix in women with perineal condyloma: A preliminary study

Capillary hemangioma of the orbit: The role of computed tomography

\section{Books}

continued from page $544 / 71$

herbs and related remedies. (Suitable for the layperson.) By Varro E. Tyler; pp. 254; George F. Stickley Company, 210 West Washington Square, Philadelphia 19106, $1987, \$ 18.95$ (paper).

Hospital-sponsored health maintenance organizations: Issues for decision makers. Edited by Gary J. Rahn; pp. 254, with illus.; American Hospital Publishing, Inc., 211 East Chicago Avenue, Chicago $60611,1987, \$ 45.00$ (AHA members $\$ 35.00$ ) (paper).

Handbook for hospital secretaries. (Includes a chapter covering common styles of bibliographic citations used by most medical journals.) By Ann E. Lobdell; pp. 187, with illus.; American Hospital Publishing, Inc., 211 East Chicago Avenue, Chicago 60611, 1987, \$19.95 (AHA members \$15.95) (wirebound).

\section{New members}

Bagby, Martin D., COMS '77; 2255 John F. Kennedy Rd., Dubuque, IA 52001

Bayer, Jay D., PCOM '70; 17 W. Baltimore St., Greencastle, PA 17225

Chilton, Barbara Gene, OCOMS '82; No. 410, 2301 Beau Monde Ln., Lisle, IL 60532

Cullen, Edward J., Jr., PCOM '79; Dakota Clinic, Ltd., 1702 S. University Dr., Fargo, ND 58103

Donlick, Richard J., PCOM '79; Box 7, 109 Church St., Groton, NY 13073

Goodman, D. Jeffrey, NYCOM '82; 3184B S. Congress Ave., Palm Springs, FL 33461

Johnson, Vincent G., Capt., UHSCOM '83; No. 304, 1022 Navarro St., San Antonio, TX
78205

Lash, Jeffrey W., KCOM '76; Dept. of Family Practice, Box 193, Farmer City, IL 61842

Lewen, Marc K., KCOM '81; 2200 West Port Plaza, Suite 212, St. Louis, MO 63146

Malecka, James J., PCOM '77; 7 Willow St., Williamstown, NJ 08094

Pershkow, Joel, KCOM '67; 1881 N.E. 164th St., North Miami Beach, FL 33162

Stein, Joseph S., MSUCOM '73; 303 Beckley Ln., Dublin, OH 43017

Wang, Charles W.C., KCCOS '65; 2225 E. Grand Blanc Rd., Box 646, Grand Blanc, MI 48439

Williams, Vickie S., Capt., UHSCOM '81; 18493 E. Belleview $\mathrm{Ln}$., Aurora, CO 80015 